\title{
LIBRARY NETWORK ANALYSIS AND PLANNING (LIB-NAT)
}

Maryann DUGGAN: Director, Industrial Information Services Program, Southern Methodist University, Dallas, Texas

A preliminary report on planning for network design undertaken by the Reference Round Table of the Texas Library Association and the State Advisory Council to Library Services and Construction Act Title III Texas Program. Necessary components of a network are discussed, and network transactions of eighteen Dallas area libraries analyzed using a methodology and quantitative measures developed for this project.

To be a librarian in 1969 is to stand at the crossroads of change, with a real opportunity to put libraries and professional experience to work on immediate problems of today's world. In mobilizing total library resources for effective service to a variety of patron groups in a variety of ways, the librarian has at hand an exciting new tool of great potential and equally great challenge: the library network.

\section{LIBRARY NETWORKS AND REFERENCE SERVICES}

Networks and all that they imply are simply an extension of good reference services as they have been practiced for years, but their existence and potential capability require redefinition of the reference function, which, being no longer limited to one collection, has been given new dimensions of time, depth and breadth.

Networks, and the inter-library cooperation they require, offer an opportunity to combine materials, services and expertise in order to achieve more than any one library can do alone. In this case, the whole is greater than the sum of its parts, for each library can offer its particular patron group the total capability of the network, including outside resources not previously available. 
With the new tool of library networks, it is possible to provide responsive, personalized, in-depth reference service, and to provide it so rapidly that a patron can receive a pertinent bibliography covering his desired topic within an hour of his original inquiry. The reference librarian becomes an expert in resources and resource availability at the national level. His reference desk becomes a switching center, at which he receives and analyzes inquiries, decides the level of service required, identifies available sources or resources that match an inquiry, transmits the latter (restructured to be compatible with the network language), conducts a dialog with the source, receives the response and interprets it to the patron. This procedure is not markedly different from what has been done for years in any reference library, but with greater potential the process must be more formalized and structured.

Networks do require new expertise and crystallizing the reference philosophy. Clarification is needed as to 1) types or levels of reference services, and unit operations in reference services; 2) the role of in-depth subject analysis of reference queries; 3 ) decisions on alternate choices of sources and of communications links; 4) structuring of large blocks of resources to permit fast access; and 5) the role of each library in the network and its responsibility to the network.

\section{APPROACH TO NETWORK DESIGN}

The Reference Round Table of the Texas Library Association and the State Advisory Council to Library Services and Construction Act Title III Texas Program have been struggling with the challenge of inter-library network design for the past two years. This paper is written to share with reference librarians some of their preliminary findings and to urge the involvement of reference librarians in planning and developing networks and network parameters. For identification the project herein described is referred to as Lib-NAT, for Library Network Analysis Theory.

Although only the author can be blamed for any faults of this "theory," many persons have contributed to the development of it. The Reference Round Table of the Texas Library Association has provided the forum for exploring and developing ideas on inter-library cooperation. Title III of the Library Services and Construction Act has provided the legal and financial impetus enabling the field testing of some of those ideas. Texas Chapter, Special Libraries Association, has sparked and catalyzed ideas and clarified needs. The State Technical Services Act provided the vehicle for experimental development of new approaches to reference services. Southern Methodist University provided the haven and ivory tower from which these new approaches could be tried under the cloak of academic respectability. But, of greatest importance of all, individual librarians, with vision and desire to be of service and willingness to try new things, have been the driving force in helping to develop new concepts of library use and purpose in the Texas area. 
The basic philosophy back of Lib-NAT is simply that any person anywhere in the State of Texas should have access to any material in any library anywhere in the State through a planned, orderly, effective system that will preserve the autonomy of each library while serving the needs of all the citizens of the State. Particular needs of special user groups (such as the blind or the accelerated student or the industrial researcher) should also be identified and provided for in a cooperative mode through local libraries throughout the State.

\section{NETWORK COMPONENTS}

In the process of developing Lib-NAT, twelve critical components were identified that are essential to orderly, planned development of the objectives stated above. As a minimum, such a network must have the following:

1) Organizational structure that provides for fiscal and legal responsibility, planning, and policy formulation. It must require commitment, operational agreement and common purpose.

2) Collaborative development of resources, including provision for cooperative acquisition of rare and research material and for strengthening local resources for recurrently used material. The development of multi-media resources is essential.

3) Identification of nodes that provide for designation of role specialization as well as for geographic configuration.

4) Identification of primary patron groups and provision for assignment of responsibility for library service to all citizens within the network.

5) Identification of levels of service that provide for basic needs of patron groups as well as special needs, and distribution of each service type among the nodes. There must be provision for "referral" as well as "relay" and for "document" as well as "information" transfer.

6) Establishment of a bi-directional communication system that provides "conversational mode" format and is designed to carry the desired message/document load at each level of operation.

7) Common standard message codes that provide for understanding among the nodes on the network.

8) A central bibliographic record that provides for location of needed items within the network.

9) Switching capability that provides for interfacing with other networks and determines the optimum communication path within the network.

10) Selective criteria of network function, i. e., guidelines of what is to be placed on the network.

11) Evaluation criteria and procedures to provide feedback from users and operators and means for network evaluation and modification to meet specified operational utility. 
12) Training programs to provide instruction to users and operators of the system, including instruction in policy and procedures.

The foregoing components of the ideal inter-library network (one so designed that any citizen anywhere in the state can have access to the total library and information resources of the state through his local library) may be considered the conceptual model, or the floor plan from which the network of the program can be constructed. Although these twelve components might be labeled "ideal," they are achievable and they are within reach of the present capability of all libraries today. They have also weathered the unrelenting critique of 288 reference librarians in the March 27, 1969, TLA Reference Round Table ("The 1969 Reference Round Table Pre-Conference Institute: An Overview," Texas Library Journal, Vol. 45 (Summer 1969), No. 2.). During that Reference Round Table the twelve components were tested in a simulated network, using 42 cases. In this behavioral model actual, current inter-library practices were observed during game-playing in the simulated network. The experience verified that the components outlined above are essential to the development of planned, cooperative, inter-library systems.

\section{ANALYSIS OF NETWORK TRANSACTIONS}

As part of the LSCA Title III project, and to test the twelve components, exploration was instituted into the existing inter-library relations among eighteen libraries of all types in the Dallas area to see how current practices compared with the ideal conceptual model. The essential minimum requirement of a library is document transfer, i. e., the ability to supply a known item on request; and on-going inter-library loan transactions are a valid indicator of emerging network patterns in the current environment.

This microscopic study of 1967 individual library loans among eighteen libraries of different types has provided a wealth of insight into network developments. As a pilot model it has offered a means of observing and studying existing practices, identifying problems, and experimentally evaluating the effect of changes in the system or environment. More must be known about on-going inter-library transactions for the design of improved networks. In the attempt to find out who was attempting to borrow what from whom and how successfully requests were filled, the following variables were considered:

1) Type of library, both borrowing and lending, such as academic, public, special, or public school.

2) Type of message format, i. e., telephone, TWX, TELEX, letter, or interlibrary loan.

3) Type of item requested in the transaction, such as monograph, serial, map, document.

4) Geographic location of borrowing and lending library, i. e., local, area, state, regional, national or international. 
The complexity of even a small pilot model required the formulation of some rigor in the analysis and the development of analytical tools and symbolic models. Figure 1, for example, is a symbolic model that permits comparison of two variables simultaneously, e. g., the type of library participating in the transactions and the geographic level of the participants. For modeling purposes, it was assumed all libraries fall into one of four

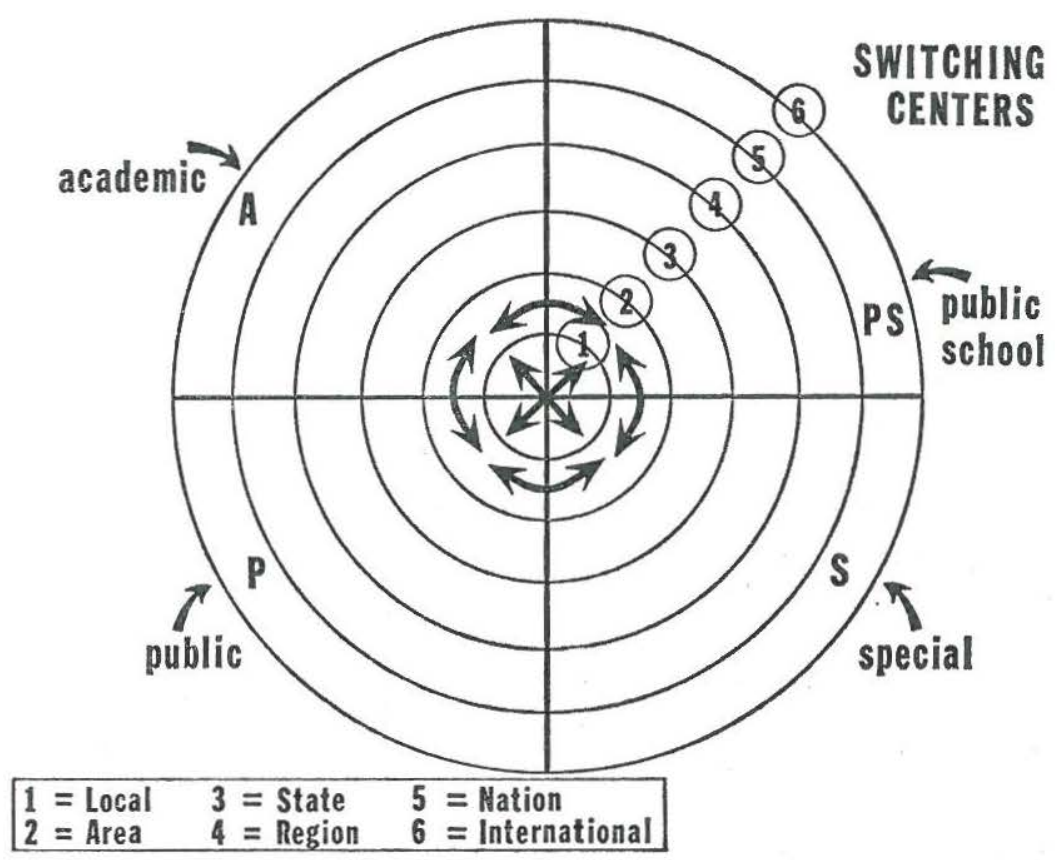

Fig. 1. Symbolic Model of Inter-Library Networks.

classes represented by the quadrants in Figure 1. Also it was assumed that each library can be identified as to a specific geographic level, as indicated by the numbers 1 through 6 . In the analysis of the pilot model data it was observed that transactions occur among libraries of the same type and at the same geographic level, and between libraries of different types at different geographic levels. Figure 1 provides a symbolic model for conceptualizing these various types of transactions. Switching centers, represented on Figure 1 by the circles around the geographic numbers, participate in transactions at varying geographic levels, as well as between and among various types of library sectors. The role and the location of switching centers is an important aspect of Lib-NAT. 
Within the framework of the symbolic model, the simple form of interlibrary loan may be represented as a two-body transaction between the borrowing library and the lending library, as shown in Figure 2. Applying these transactions on the symbolic model of Figure 1 and considering both

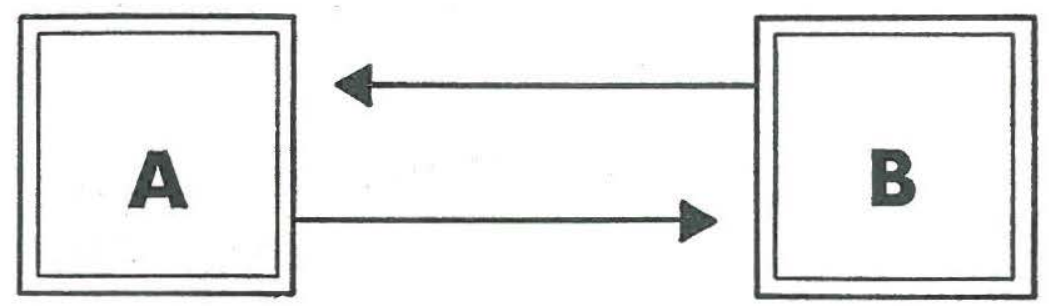

Fig. 2. Two-Body Transaction.

type of library and geographic level, four general classes of two-body transactions can be identified:

1) Homogeneous vertical, i. e., between two libraries of the same type but at different geographic levels $\left(\mathrm{P}_{1} \rightarrow \mathrm{P}_{4} ; \mathrm{S}_{1} \rightarrow \mathrm{S}_{3}\right)$;

2) Heterogeneous horizontal, i. e., between two different types of libraries at different levels $\left(P_{1} \rightarrow A_{1} ; S_{1} \rightarrow P_{1}\right)$;

3) Heterogeneous vertical, i. e., between two different types of libaries at different levels $\left(\mathrm{P}_{1} \rightarrow \mathbf{A}_{4} ; \mathrm{S}_{1} \rightarrow \mathrm{P}_{5}\right)$;

4) Homogeneous horizontal, i.e., between two libraries of the same type and the same geographic level $\left(\mathrm{P}_{1} \rightarrow \mathrm{P}_{1} ; \mathrm{S}_{2} \rightarrow \mathrm{S}_{2}\right)$.

The formulas serve as a shorthand symbolic representations of some typical transactions of these four classes. The final report on Lib-NAT will contain statistical data on distribution of pilot model transactions by type and by geographic level, showing type interdependency and geographic dependency or self-sufficiency.

Further analysis of the pilot model data revealed another type of transaction, the three-body transaction, in which a third agent becomes involved. The third agent may act as a referral center, as illustrated in Figure 3, or as a relay center, as illustrated in Figure 4 (SW indicates switching center). Part of the Lib-NAT theory specifies that there is a distinction between referral and relay, and that the latter is a valid function of a true switching center. Figure 5 illustrates the various types of possible three-body transactions with different geographic levels of switching among the different types of libraries. Which of these transactions is the most efficient or has the greatest utility is one of the basic design parameters needing further analysis. It should be noted that the variable of message format, that is, the channel of communication or type of communication link, has not yet been investigated in the symbolic modeling of these transactions. 




Fig. 3. Three-Body Transaction: Referral.

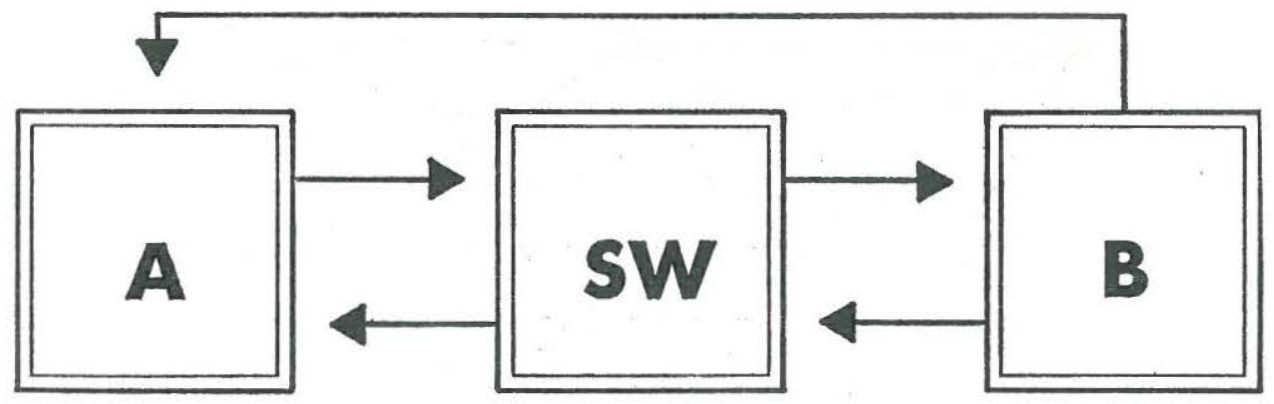

Fig. 4. Three-Body Transaction: Relay.

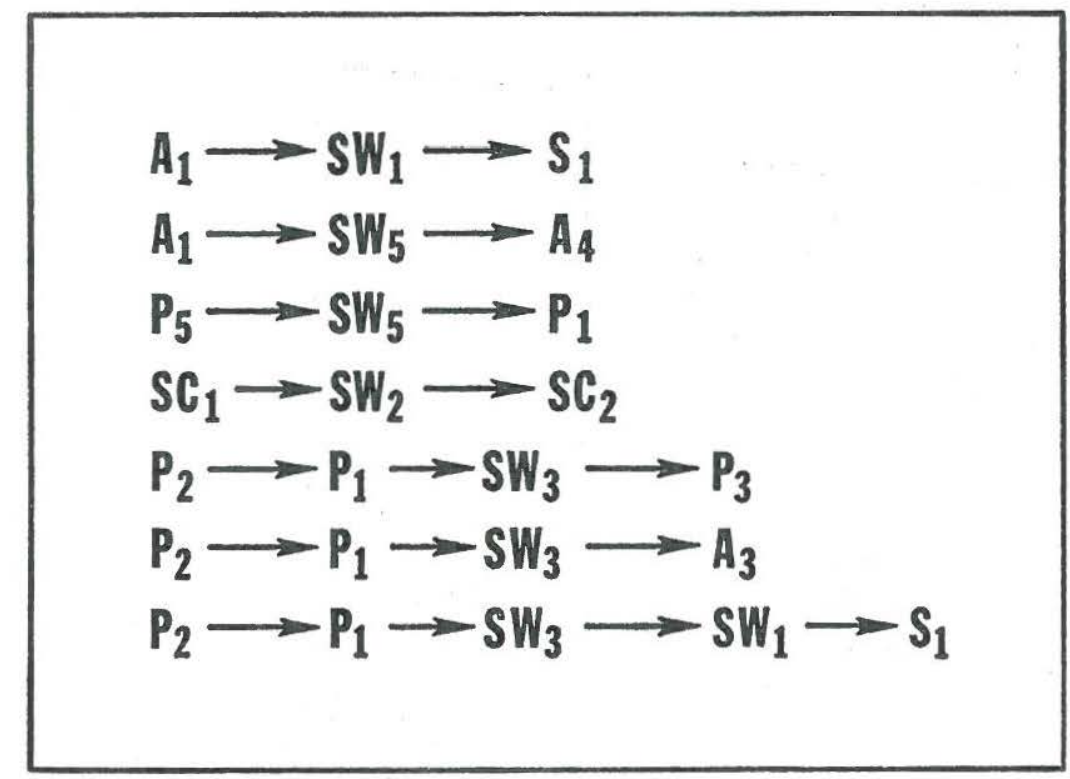

Fig. 5. Three-Body Transactions at Various Geographic Levels. 


\section{NETWORK CONFIGURATION}

Another very important design parameter is the network configuration or organizational hierarchy specifying the communication channels and message flow pattern. Figure 6 illustrates symbolically a non-directed configuration of communication. If each dot represents a node in the network (i. e., a participating library), and each line represents a communication link, it can be seen that each node can communicate directly with every other node, providing (or requiring) a total of fifteen links among the six nodes.



Fig. 6. Non-Directed Network.

By contrast, Figure 7 illustrates a directed configuration to which the six nodes are interconnected through a switching center and requiring only six channel links. In like manner, if a non-directed network desires to interface with a specialized center, such as the Library of Congress or a special bibliographic center or search center, a total of twenty-one channels is required (Figure 8), whereas a directed network can interface with a specialized center via only seven channels, as illustrated in Figure 9.

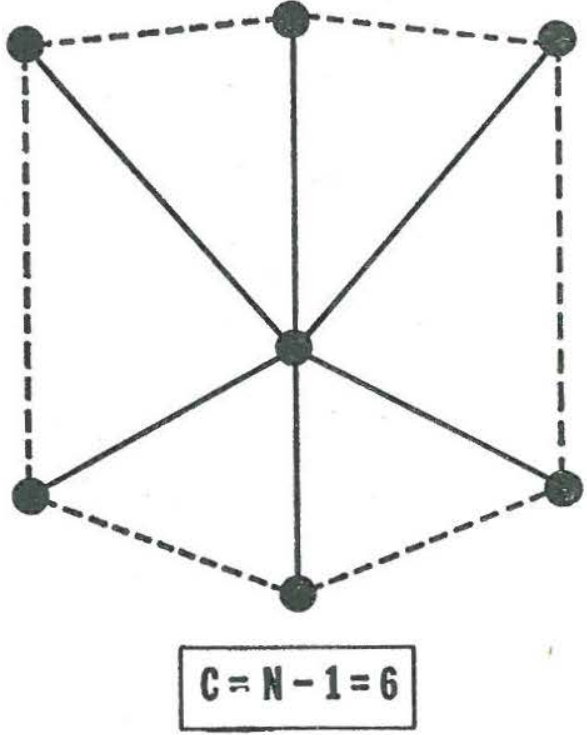

Fig. 7. Directed Network. 


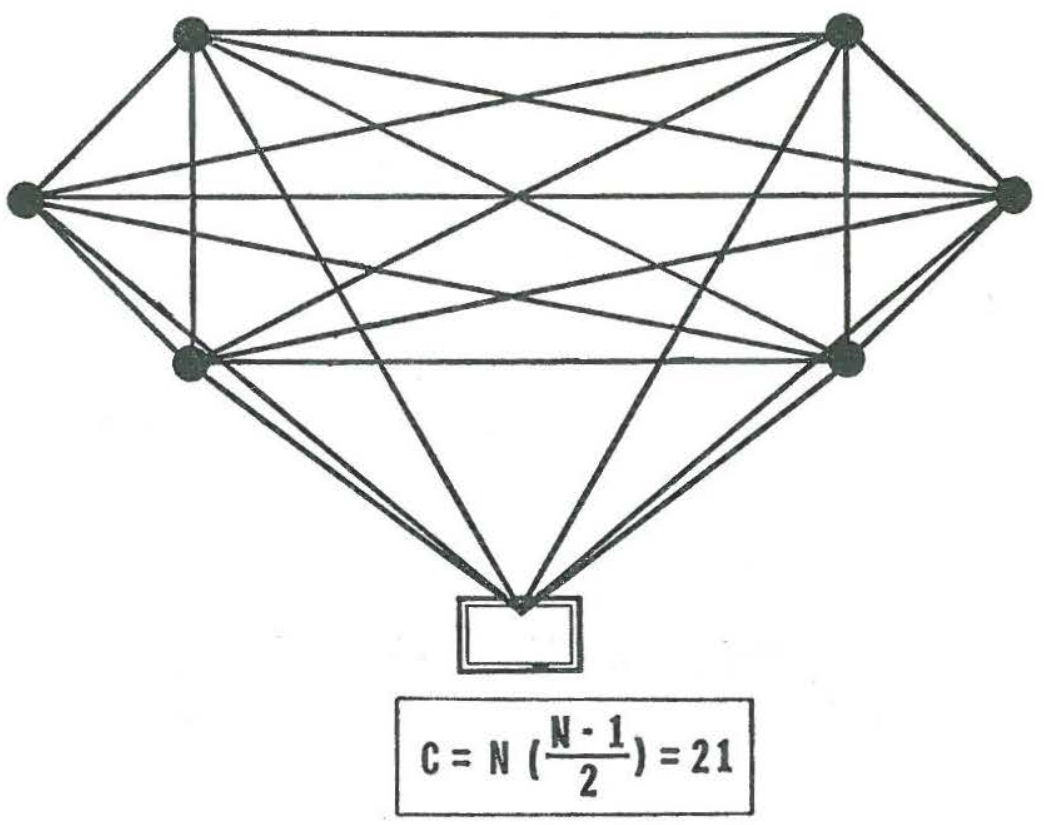

Fig. 8. Non-Directed Network Including Specialized Center.

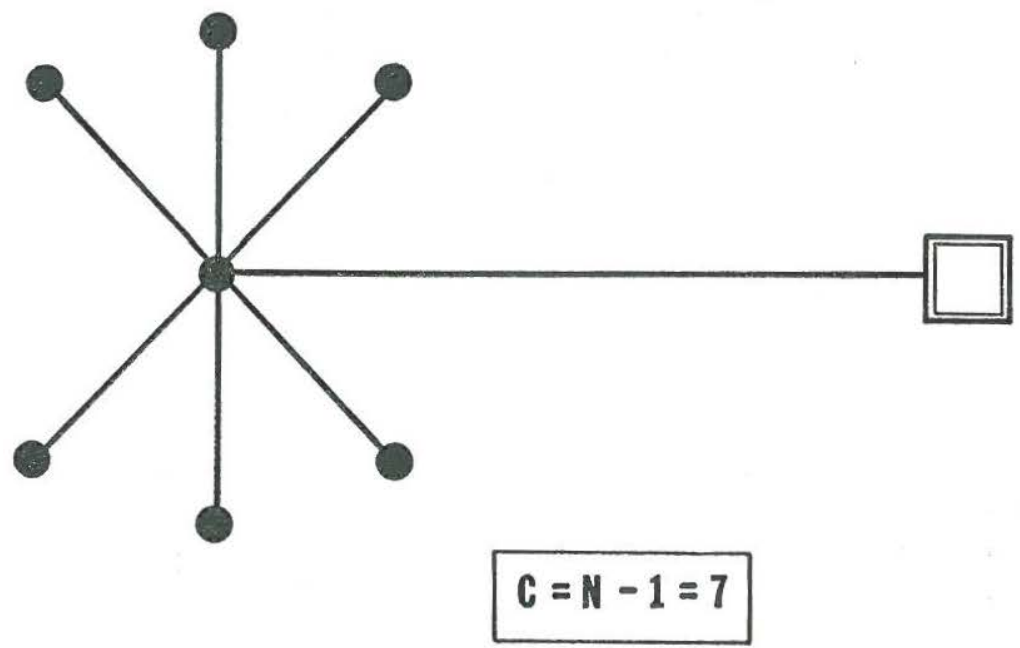

Fig. 9. Directed Network Including Specialized Center. 
As local or area networks begin to develop, there will be a need for tying together two area networks to develop larger units of service. The interfacing of an original network of six libraries in one area with an adjoining area network of six libraries will result in the network configuration shown in Figure 10 in the case of a non-directed network, and sixty-six communication links among twelve nodes will be required. Whereas, if two directed networks of six libraries each desire to interface, a type of linkage requiring only thirteen channels may be envisioned (Figure 11).

Which is the best type of network configuration? What are the decision parameters that should be considered in designing or planning network configuration? How can alternate configurations be evaluated? Alternate channel requirements? And alternate geographic levels of switching? In the pilot model study, a mathematical model has been devised which can be used for simulating various configurations and channel capacities,

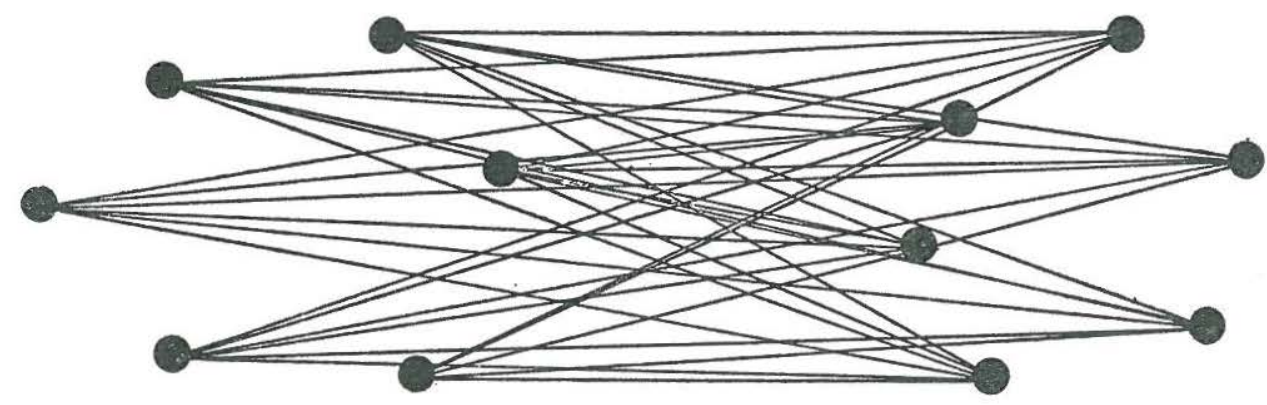

$$
C=12\left(\frac{12 \cdot 1}{2}\right)=66
$$

Fig. 10. Interface of Two Non-Directed Networks.

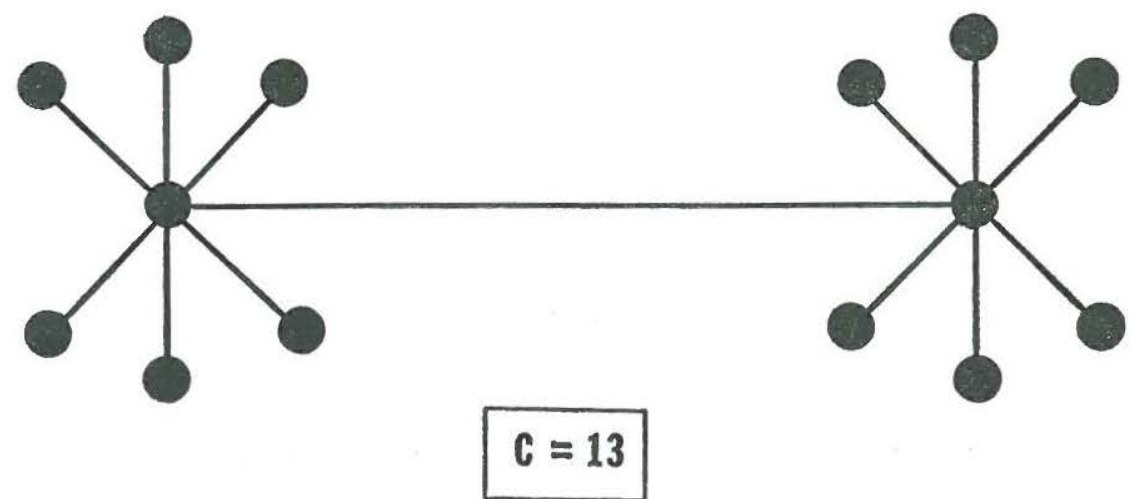

Fig. 11. Interface of Two Directed Networks. 
thereby permitting some desired criteria function of network performance to be maximized or optimized. The details of the mathematical model will be published as part of the final report on Lib-NAT; in the meantime it can be said that this is a fascinating area of network analysis which will be useful to any group of libraries planning network configurations. The mathematical model-a multi-commodity, multi-channel, capacitated network model, developed by Dr. Richard Nance at Southern Methodist University as part of the Title III project-promises to have a high potential application in network design and performance evaluation. It does require that the librarian make some hard-nosed decisions on operational and performance parameters of the inter-library systems discussed in the preceding article, but this is part of the challenge of Lib-NAT.

\section{MEASURES OF PARTICIPATION}

It is obvious that types of libraries, geographic level, types of transactions, various network configurations, alternate communication links and switching levels are all important in planning inter-library systems. Next it is necessary to take an in-depth look at the relationship between the individual participating library and the total network. In the pilot model study of eighteen libraries a noticeable difference appeared in the magnitude and type of participation. In surveying only the two-body transactions, it was observed that some libraries were primarily borrowers and others primarily lenders, and some were heavy and some light. In pursuit of a quantitative method of representing these relationships some formulae were evolved which are helpful in understanding node/network dynamics.

Starting with the individual library or node, let $B_{n}$ equal the number of borrowing transactions originating at that node and $L_{n}$ equal the number of lending transactions; then $L_{n}$ plus $B_{n}$ will equal the total number of all transactions at that particular node.

In like manner, looking at the total network (in this case all eighteen participating libraries), let $B_{t}$ equal the total number of borrowing transactions originating in the network and $L_{t}$ the total number of lending transactions; then $B_{t}$ plus $L_{t}$ will equal the total number of both types of transactions in the network.

In the analysis of node/network dynamics, it was felt there should be some way of quantitatively expressing the individual node's dependency on the total network and also a way of expressing the relative degree of activity of each node. In other words, a participating library that was a net borrower (compared to its lending) was obviously more dependent on the network than would be a library that borrowed very little compared to its lending. The extent of dependency can be expressed as a node dependency coefficient calculated as follows:

$$
\frac{B_{n}}{B_{n}+L_{n}}=\begin{aligned}
& \text { Relative amount of } \\
& \text { borrowing compared to } \\
& \text { total node transactions }
\end{aligned}
$$


Among its other uses, the dependency coefficient of a node may give some insight into the extent to which it should share in network expenses, but the dependency coefficient alone should not be a final criterion, since magnitude of activity is of equal importance. For developing a method of quantitatively expressing activity of a node compared to total activity of the network a factor called the node activity coefficient may be calculated as follows:

$$
\frac{B_{n}+L_{\mathrm{n}}}{B_{t}+L_{t}}=\begin{aligned}
& \text { Relative activity of both types at } \\
& \text { one node compared to total activity } \\
& \text { in total network }
\end{aligned}
$$

Then, to quantitatively express the dependency of a given node on the network, one can calculate the node/network dependency coefficient as follows:

$$
\frac{B_{n}}{B_{t}+L_{t}}
$$

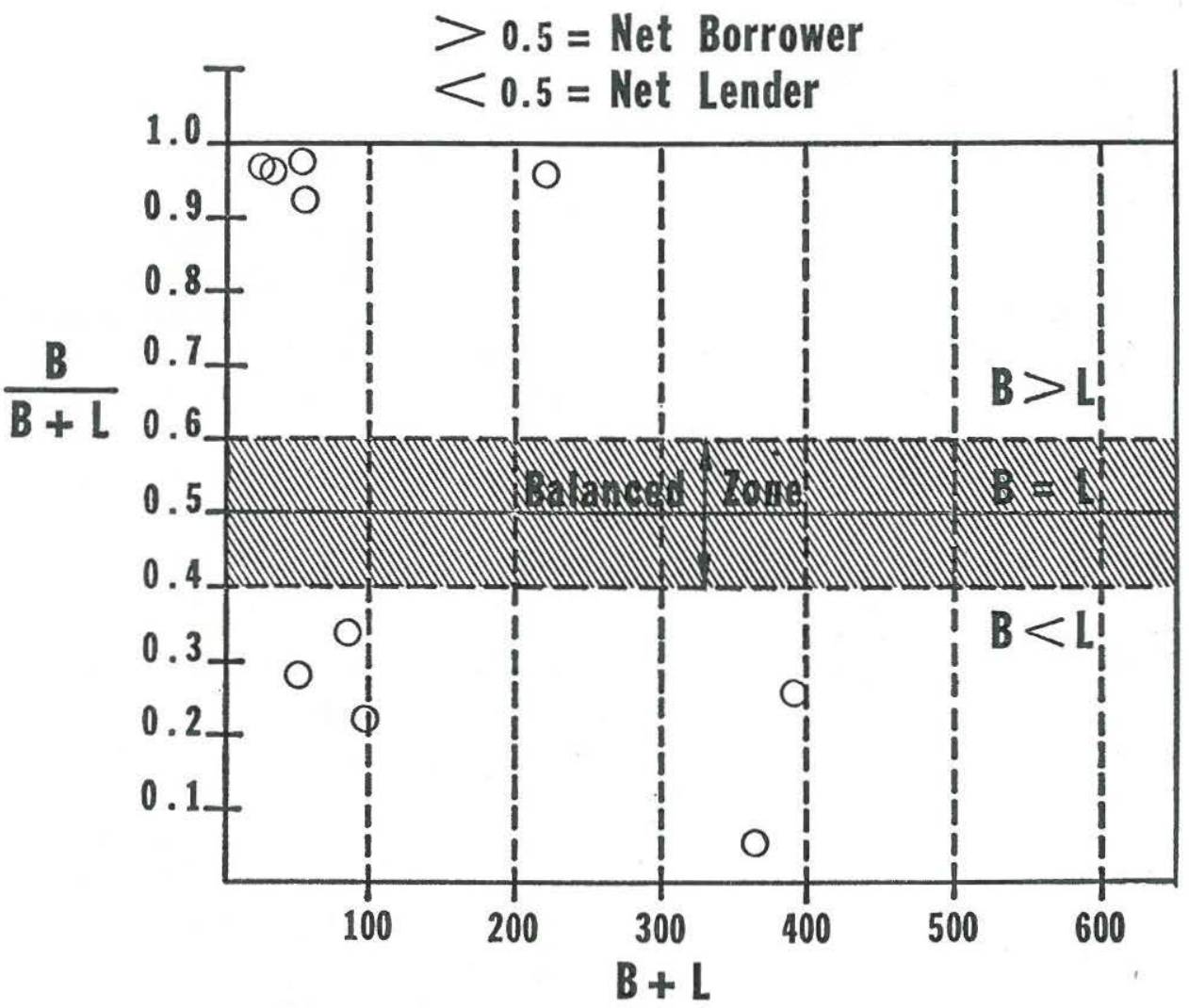

Fig. 12. Node Dependency Coefficient. 
Figure 12 illustrates one use of the data points expressed above. Plotting the node dependency coefficient versus the total transactions at the nodes readily reveals the differences in the relationships between them and the network. What the relationship should be is a value judgment that is open to conjecture, but if it is assumed that theoretically each node should be in some sort of balance between borrowing and lending, it is possible to construct a balance zone based on ten percent leeway from perfect balance. By zoning various levels of activity vertically, one can develop a quantitative grid for comparing network participants' activity, both give and take, and can possibly arrive at a funding structure for network financing. The dots in Figure 12 illustrate data points from the pilot model.

Figure 13 shows another application of quantitative data on node/network relationships. By plotting the node dependency coefficient on the left and the node activity coefficient on the lower axis, one can see individual differences easily and readily compare relative participation. Certainly, a node with a 1-1 plot is more dependent on the network than a node with an 0.1-0.1 plot.
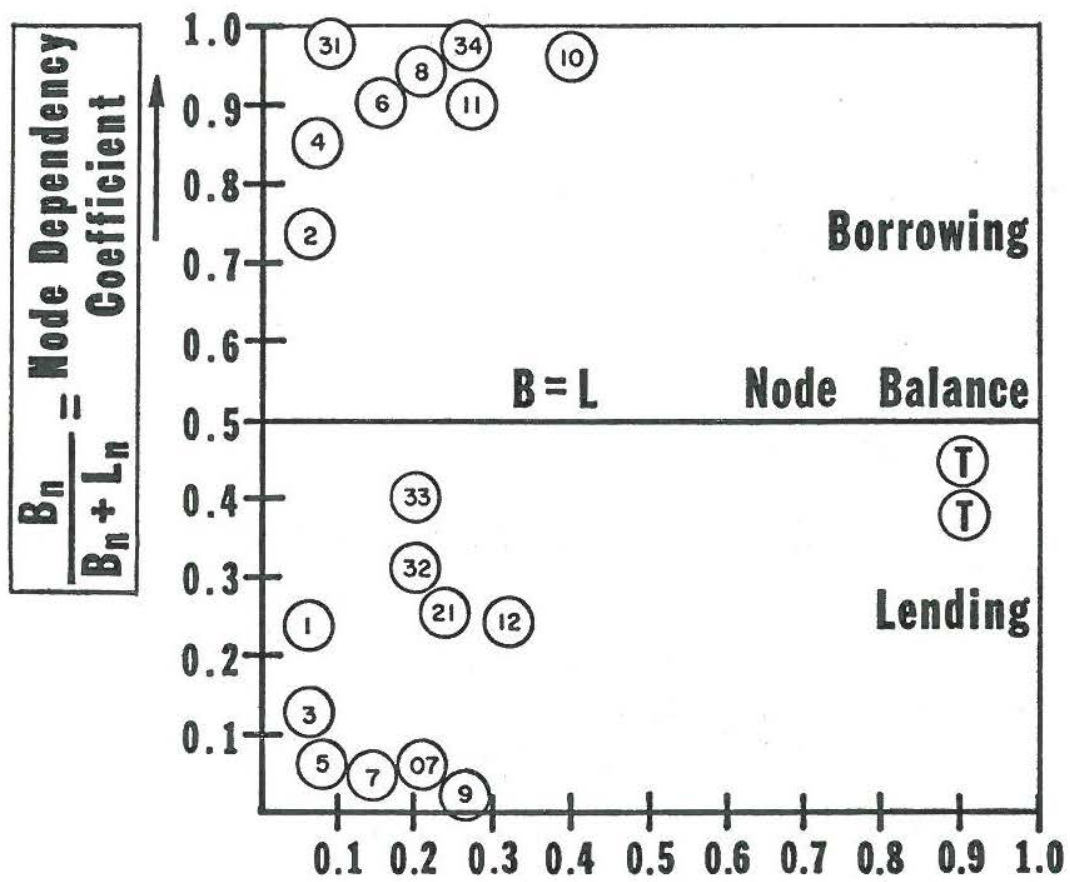

$\frac{B_{n}+L_{n}}{B_{t}+L_{t}}=\begin{gathered}\text { Node Activity } \\ \text { Coefficient }\end{gathered}$

Fig. 13. Network Dynamics. 


\section{NETWORK PERFORMANCE}

In evaluating the performance of a network there are three key factors to consider: 1) turn-around time, meaning the time required to complete a transaction or satisfy a request; 2) the cost of completing the transaction or satisfying the request, including fixed and variable cost; and 3) quality, the all-important criterion of how well the job is done, based on patron satisfaction or other standards. These three factors are interrelated but can be quantitatively identified, as illustrated schematically in Figure 14.



\section{QUALITY}

TIME

Fig. 14. Network Utility Factors.

It may be seen here that one network might demonstrate average quality, high cost and fast time, whereas another network might demonstrate average quality, low cost and slow time. It is suggested that this technique of interrelating time, cost and quality is useful in evaluating and comparing network performance. Certainly it is necessary to consider all three factors in defining network utility and network operational parameters.

The several methodologies described above were used to analyze the performance of the eighteen libraries participating in the study. Preliminary results are disturbing. For example, the range of unfilled requests was from 76 percent in public libraries to 2.5 percent in medical libraries, for an average of 23 percent. Node dependency coefficient ranged from 1.0 in junior colleges and 0.97 in industrial libraries to a low of 0.27 in medical libraries. The range in activity coefficient was from zero in county libraries to 0.2 in medical libraries. It is to be hoped that further analysis 
will provide insight into ways of improving services and evolving performance standards for networks.

\section{SUMMARY}

The Lib-NAT approach provides a methodology for looking at interlibrary cooperation and network design. Some of the quantitative tools offered may not be applicable to every situation; some of the hypotheses may prove to be in error, but the ultimate goal of the exercise is to improve services to users. Thus the last point in Lib-NAT is probably of greatest significance to all.

In it one may recognize an old rule of thumb in book selection: the right book to the right person at the right time. Looking at the heart of network performance as illustrated in Figure 15, it can be seen that a system is performing "right" when there is a match of the patron group (a) with the library type (b) and the nature of the request (c). The combination of the three may be called a "hit" and is of utmost importance in determining what to put on the network and where to direct the request, and what to seek and for whom.



Fig. 15. Parameters of Network Selectivity Policy.

Librarians are just beginning to understand that inter-library networks offer not only a great potential to improve and expand services, but a whole new dimension in reference services as well. The purpose of LibNAT is to help formulate the rules of this new "ball game." 


\section{NOTE}

The final report on this project will include the full script of the Reference Round Table networking game; a glossary of networking terms; the computer programs for computing and graphing inter-library network coefficients; and the details of the operations research model of library networks. A copy of the final report on Lib-NAT may be had after September 15, 1969, from Mrs. Marie Shultz, Texas State Library, Austin, Texas, or from the author.

\section{ACKNOWLEDGMENTS}

Miss Janice Kee, Regional Program Officer, Office of Education, Dallas, Texas, provided encouragement and critical insight. Mrs. Marie Schultz, Head of Field Services Division, Texas State Library, Austin, supported the project as part of the Texas State Plan under LSCA Title III.

Dr. Richard Nance, Professor, Institute of Technology, SMU, and Mr. Carl Peters, Programmer, Southwest Center for Advanced Studies, Dallas, contributed mathematical and programming skills. The figures were prepared with the assistance of Mrs. Mickey Boyvey, Library Coordinator, Texas Education Agency, Austin, Texas.

The author wishes to express particular appreciation to the eighteen librarians who collected the data on interlibrary transactions and assisted in the planning of the pilot model.

\section{BIBLIOGRAPHY}

Following is a preliminary partial bibliography on inter-library networks, modeling and simulation, and other problem-solving methods.

\section{Networks and Networking}

1. Becker, Joseph: "Communications Networks for Libraries," Wilson Library Bulletin, 41 (Dec. 1966), 383-387.

2. McElderry, Stanley: "Interstate Highways of the Mind-Library Networks," Special Libraries Association, Texas Chapter. Bulletin, 20 (Nov. 1968), 13-24.

3. Texas State Library: Major Resources Center Communication Network Study. Prepared for the Texas State Library by Management Research International, Inc. (Austin, Texas: 1967), 40 p.

4. Brown, George W.; et al.: EDUNET: Report of the Summer Study on Information Networks Conducted by EDUCOM (New York; Wiley, 1967), $440 \mathrm{p}$.

5. Becker, Joseph; Olsen, Wallace C.: "Information Networks," Annual Review of Information Science and Technology, 3 (1968), 289-327.

6. Becker, Joseph; Hayes, Robert M.: A Proposed Library Network for Washington State: Working Paper for the Washington State Library (Washington State Library, 1967), 50 p. 
7. Calahan, Donald Albert: Computer-Aided Network Design; preliminary ed. (New York: McGraw-Hill, 1968), 295 p.

8. Knox, William T.: "Toward National Information Networks," Physics Today, 19 (Jan. 1966), 38-60.

9. Carnovsky, Leon, ed.: "Library Networks: Promise and Performance," Library Quarterly, 39 (Jan. 1969), 306-317.

10. Becker, Joseph: "Information Network Prospects in the United States," Library Trends, 17 (Jan. 1969), 306-317.

11. Gruenberger, Fred, ed.: Computers and Communications-Toward a Computer Utility (Englewood Cliffs, N. J.: Prentice-Hall, 1968), $219 \mathrm{p}$.

12. Ford, L. R., Jr.; Fulkerson, D. R.: Flows in Networks (Princeton, N. J.: Princeton University Press, 1962).

13. "The National Network of Information Centers." In Overhage, Carl F. J.; Harman, R. Joyce, eds.: INTREX; Report of a Planning Conference on Information Transfer Experiments (Cambridge, Mass.: M. I. T. Press, 1965), 276 p.

14. Emling, J. W.; et al.: "Library Communications Networks." In Conference on Libraries and Automation, Airlee Foundation, Warrenton, Va., 1963: Proceedings . . . Libraries and Automation, ed. by Barbara Markuson (Washington: Library of Congress, 1964), 268 pp.

15. Kilgour, Frederick G.: "Research Libraries in Information Networks." In National Colloquium on Information Retrieval, 2d, 1964: Toward a National Information System (New York: Spartan Books, 1965), pp. 147-154.

16. Swanson, Rowena: “Information System Networks; Let's Profit from What We Know." In National Colloquium on Information Retrieval, 3d, Philadelphia, 1966: Information Retrieval; a Critical Review (Washington: Thompson Book Co., 1967), pp. 1-52.

17. Wall, Eugene: "Possibilities of Articulation of Information Systems into a Network," American Documentation, 19 (April 1968), 181-187.

18. Texas Library Association, Reference Round Table; Pre-Conference Seminar on Reference Services in Texas Libraries, San Antonio, 1968: Proceedings (Houston, Texas: Phil Wilson, 1968), $52 \mathrm{p}$.

19. Tschirgi, Robert D.: "Regional and National Networks." In Computers and Education, ed. by R. W. Gerard (New York: McGraw-Hill, 1967), $307 \mathrm{p}$.

20. Carter, Launor F.; et al.: National Document-Handling Systems for Science and Technology (New York: Wiley, 1967), 344 p.

Modeling, Simulation, and Other Problem-Solving Methods

1. Berrien, F. Kenneth: General and Social Systems (New Brunswick, N. J.: Rutgers University Press, 1968), 231 p.

2. Berne, Eric: Games People Play; the Psychology of Human Relationships (New York: Grove Press, 1964), pp. 1-67. 
3. "Concept and the Role of the Model in Mathematics and Natural and Social Sciences." In Freudenthal, Hans, ed.: Proceedings of $a$ Colloquium... (New York: Gordon and Breach, 1961), 194 p.

4. Case Institute of Technology, Systems Symposium, 2d, 1963: Views on General Systems Theory (New York: Wiley, 1964), $178 \mathrm{p}$.

5. Symposium on Methodologies, Pasadena, Calif., 1967: New Methods of Thought and Procedure (New York: Springer, 1967).

6. Deacon, Amos R. L., ed.: Simulation and Gaming: A Symposium (New York: American Management Association, 1961). AMA Management Report No. 55.

7. Emory, William; Niland, Powell: Making Management Decisions (Boston: Houghton Mifflin, 1968), 306 p.

8. Blake, Robert R.: The Managerial Grid; Key Orientations for Achieving Production through People (Houston, Texas: Gulf Pub. Co., 1964), pp. 1-17.

9. Martin, Francis F.: Computer Modeling and Simulation (New York: Wiley, 1968).

10. Gue, Ronald L; Thomas, Michael E.: Mathematical Methods in Operations Research (New York: Macmillan, 1968), 385 p.

11. Berge, Claude: The Theory of Graphs and Its Applications (New York: Wiley, 1962), $247 \mathrm{p}$.

12. Kaufmann, Arnold: Graphs, Dynamic Programming, and Finite Games (New York: Academic Press, 1967), 484 p.

13. Chernoff, Herman: Elementary Decision Theory (New York: Wiley, 1959), 364 p.

14. Munkres, James: "Algorithms for the Assignment and Transportation Problems," Society for Industrial Applied Mathematics Journal, 5 (March 1957), 32-38.

\section{Applications}

1. Pings, Vern M: Interlibrary Loans: A Review of the Library Literature, 1876-1965 (Detroit: Wayne State Univ., 1966). PB-179755.

2. Cziske, Clara; Pings, Vern M.: A Study of Interlibrary Loans at Sinai Hospital of Detroit, July to December 1965 (Detroit: Wayne State Univ., 1966). PB-179757.

3. Orr, Richard; et. al.: "Development of Methodologic Tools for Planning and Managing Library Services. Pt. 1. Project Goals and Approach. Pt. 2. Measuring a Library's Capability for Providing Documents," Bulletin of the Medical Library Association, 56 (July 1968), 235-267.

4. Nance, Richard E.; Baker, Norman R.: An Industrial Dynamics Model of a University Library (Oct. 1968), 35 p. Report on NSF Grant GN-519. 
5. Nance, Richard; Baker, Norman: "The Use of Simulation in Studying Information Storage and Retrieval Systems," American Documentation, 19 (Oct. 1968), 363-370.

6. Morse, Philip M.: "Probabilistic Models for Library Operations." In Association of Research Libraries, 63rd Meeting, Jan. 1964: Minutes, 9-18.

7. Blunt, Charles; et al.: A General Model for Simulating Information Storage and Retrieval Systems (State College, Pa.: H. R. B. Singer Inc., 1966). AD-636435.

8. Chodrow, Mark; et al.: Information Service System Modeling: Analytical Tools for Management Evaluation (Information Dynamics Corp., 1963).

9. Garner, Harvey; et al.: Mathematical Models of Information Systems. Interim Report, Oct. 1965 to Oct. 1966 (Ann Arbor: University of Michigan Systems Engineering Laboratory, 1967). AD-648823.

10. Mangino, J. J.: "Library Simulation; the Computer Locates the Data Needle in the Journal Haystack," Simulation, 10 (Feb. 1968), 69-72.

11. Miller, James C.: "Conceptual Models for Determining Information Requirements." In Joint Computer Conference: Proceedings, 25 (1964), 609-620. 